\title{
Differences in risk aversion between young and older adults
}

This article was published in the following Dove Press journal:

Neuroscience and Neuroeconomics

13 February 2012

Number of times this article has been viewed

\author{
Steven M Albert' \\ John Duffy ${ }^{2}$ \\ 'Department of Behavioral \\ and Community Health Sciences, \\ ${ }^{2}$ Department of Economics, \\ University of Pittsburgh, \\ Pittsburgh, PA, USA
}

Correspondence: Steven M Albert Department of Behavioral and Community Health Sciences, Graduate School of Public Health, University of Pittsburgh, A2 I I Crabtree Hall, 120 DeSoto Ave, Pittsburgh,

PA I526I, USA

Tel + I 4I2383 8693

Fax +I 4I2383 5846

Email smalbert@pitt.edu

\begin{abstract}
Research on decision-making strategies among younger and older adults suggests that older adults may be more risk averse than younger people in the case of potential losses. These results mostly come from experimental studies involving gambling paradigms. Since these paradigms involve substantial demands on memory and learning, differences in risk aversion or other features of decision making attributed to age may in fact reflect age-related declines in cognitive abilities. In the current study, older and younger adults completed a simpler, paired lottery choice task used in the experimental economics literature to elicit risk aversion. A similar approach was used to elicit participants' discount rates. The older adult group was more risk averse than the younger $(P<0.05)$ and had a higher discount rate $(15.6 \%-21.0 \%$ versus $10.3 \%-15.5 \%, P<0.01)$, indicating lower expected utility from future income. Risk aversion and implied discount rates were weakly correlated. It may be valuable to investigate developmental changes in neural correlates of decision making across the lifespan.
\end{abstract}

Keywords: aging, decision making, risk, time preference, behavioral economics

\section{Introduction}

Evidence for greater risk aversion in decision making among older adults is accumulating but much of the evidence is indirect. For example, in the Iowa Gambling Task, older adults are less likely than younger people to learn to make the most advantageous decision over sequential trials. ${ }^{1}$ They are more likely to be influenced by recent trial results and trials in which they are successful ${ }^{2}$ and are likely to gamble similar amounts even with changes in the odds of winning. ${ }^{3}$ This conservative decision-making strategy may be related to declines in processing speed and memory. ${ }^{4}$

Other research suggests that older people are more risk averse only in certain decision contexts; that is, when weighing potential losses. ${ }^{5-7}$ In a gain frame, older and younger adults are equally likely to decide on the gamble and demonstrate no differences in risk aversion. However, in the loss frame, older adults are much less likely to gamble and are accordingly more risk averse. ${ }^{8}$ Neuroimaging and skin-conductance evidence support this age difference in the anticipation of losses but not gains. ${ }^{9}$

It would be valuable to implement experimental paradigms that allow elicitation of risk aversion directly. Here, we apply recently developed experimental economic methodologies for measuring individual risk and time preference. Estimation of risk preferences can be useful in understanding individual choices over risky outcomes and potential brain activation correlates.

Aims of this research include elicitation of differences between young adults and older people to lay the groundwork for investigation of neurobiologic changes across 
lifespan that may be relevant for decision making. We also assessed time preference in the sample to determine if risk aversion is linked with expected utility from future income, or whether these two types of preference represent distinct components of decision making with potentially different neural correlates.

\section{Methods}

\section{Sample}

Young adults were recruited from primary care or pediatric physician offices and preschool programs. Fliers were posted and clinician staff also referred potential participants. All young adult participants were mothers of young children. Older adults were recruited from senior housing sites in the same communities. All older adults were participating in other studies of health and function. Older adults meeting criteria for dementia or major depressive disorder were excluded. Both sets of participants were told they could keep their winnings from the lottery game and also received a $\$ 10$ gift certificate at a local supermarket. The Institutional Review Board at the University of Pittsburgh reviewed and approved the study protocol.

\section{Eliciting risk aversion}

We used the Holt-Laury ${ }^{10}$ paired lottery choice mechanism to measure individual risk aversion. The Holt-Laury mechanism is widely used by experimental social science researchers to measure risk aversion. To our knowledge, this mechanism has not been used to explore differences in risk aversion by age.

The paired lottery choices are presented in Table 1. Each participant makes ten choices between lotteries (labeled as "options" to participants) A or B. The expected payoff difference between lotteries A and B (indicated in the right column of Table 1) is not shown to participants, nor are the expected payoffs of either lottery calculated for them. Option A is the low variance lottery and Option B the high variance lottery. For choice 1, the probability of earning the higher payoff amount in either lottery A or B was 1/10. For subsequent choices 2, $3, \ldots, 10$, the probability of earning the higher amount increased by $1 / 10$ until choice 10 , which involved a $10 / 10$ (certain) chance of earning the higher payoff in each lottery $-\$ 20.00$ for option A and $\$ 38.50$ for option B. Individuals typically choose option A for the first few lottery choices and then switch over to option $\mathrm{B}$ for the remaining lottery choices. The final (tenth) certain choice between $\$ 20.00$ for option A and $\$ 38.50$ for option B serves as a simple rationality test.

Suppose individuals have expected utility over monetary payments, $\mathrm{x}$, of the form $u(x)=x^{1-r} / 1-r$, or $\mathrm{u}(\mathrm{x})=\mathrm{x}^{(1-r)}$,
Table I Holt-Laury paired lottery, risk aversion task

\begin{tabular}{|c|c|c|c|}
\hline Choice & Option A & Option B & $\begin{array}{l}\text { Expected payoff } \\
\text { difference } \\
\text { (choose A) }\end{array}$ \\
\hline I & $\begin{array}{l}1 / 10 \text { of } \$ 20.00 \\
9 / 10 \text { of } \$ 16.00\end{array}$ & $\begin{array}{l}1 / 10 \text { of } \$ 38.50 \\
9 / 10 \text { of } \$ 1.00\end{array}$ & $+\$ 11.65$ \\
\hline 2 & $\begin{array}{l}2 / 10 \text { of } \$ 20.00 \\
8 / 10 \text { of } \$ 16.00\end{array}$ & $\begin{array}{l}2 / 10 \text { of } \$ 38.50 \\
8 / 10 \text { of } \$ 1.00\end{array}$ & $+\$ 8.30$ \\
\hline 3 & $\begin{array}{l}3 / 10 \text { of } \$ 20.00 \\
7 / 10 \text { of } \$ 16.00\end{array}$ & $\begin{array}{l}3 / 10 \text { of } \$ 38.50 \\
7 / 10 \text { of } \$ 1.00\end{array}$ & $+\$ 4.95$ \\
\hline 4 & $\begin{array}{l}4 / 10 \text { of } \$ 20.00 \\
6 / 10 \text { of } \$ 16.00\end{array}$ & $\begin{array}{l}4 / 10 \text { of } \$ 38.50 \\
6 / 10 \text { of } \$ 1.00\end{array}$ & $+\$ 1.60$ \\
\hline 5 & $\begin{array}{l}5 / 10 \text { of } \$ 20.00 \\
5 / 10 \text { of } \$ 16.00\end{array}$ & $\begin{array}{l}5 / 10 \text { of } \$ 38.50 \\
5 / 10 \text { of } \$ 1.00\end{array}$ & $-\$ 1.75$ \\
\hline 6 & $\begin{array}{l}6 / 10 \text { of } \$ 20.00 \\
4 / 10 \text { of } \$ 16.00\end{array}$ & $\begin{array}{l}6 / 10 \text { of } \$ 38.50 \\
4 / 10 \text { of } \$ 1.00\end{array}$ & $-\$ 5.10$ \\
\hline 7 & $\begin{array}{l}7 / 10 \text { of } \$ 20.00 \\
3 / 10 \text { of } \$ 16.00\end{array}$ & $\begin{array}{l}7 / 10 \text { of } \$ 38.50 \\
3 / 10 \text { of } \$ 1.00\end{array}$ & $-\$ 8.45$ \\
\hline 8 & $\begin{array}{l}8 / 10 \text { of } \$ 20.00 \\
2 / 10 \text { of } \$ 16.00\end{array}$ & $\begin{array}{l}8 / 10 \text { of } \$ 38.50 \\
2 / 10 \text { of } \$ 1.00\end{array}$ & $-\$ 11.80$ \\
\hline 9 & $\begin{array}{l}9 / 10 \text { of } \$ 20.00 \\
1 / 10 \text { of } \$ 16.00\end{array}$ & $\begin{array}{l}9 / 10 \text { of } \$ 38.50 \\
1 / 10 \text { of } \$ 1.00\end{array}$ & $-\$ 15.15$ \\
\hline 10 & $\begin{array}{l}10 / 10 \text { of } \$ 20.00 \\
0 / 10 \text { of } \$ 16.00\end{array}$ & $\begin{array}{l}10 / 10 \text { of } \$ 38.50 \\
0 / 10 \text { of } \$ 1.00\end{array}$ & $-\$ 18.50$ \\
\hline
\end{tabular}

Notes: Participants do not see expected payoff difference. Directions: In this lottery game, you will make ten choices. For each row, you have to choose between Option A and Option B. You may choose A for some rows and B for others and you may change your decisions and make them in any order. When you are finished, we will throw a ten-sided die. The number that comes up indicates the row we will use to determine how much you win. So if the die says I and you chose Option A for this choice, you will win either $\$ 20.00$ or $\$ 16.00$. We will then roll the die a second time to see which of the two amounts you win.

when $r<1$. We can then examine the distribution of risk types by their preference parameter, $r$. A risk-neutral person has $r=0$, ie, $\mathrm{u}(\mathrm{x})=\mathrm{x}$. This type of person calculates the expected payoffs of the two lotteries without any transformation of monetary payoffs (as in the right column of Table 1). For instance, a risk-neutral person confronting lottery choice 5 compares option $A$, with an expected payoff of $0.5 \times$ $\$ 20.00+0.5 \times \$ 16.00=\$ 18$, with option $B$ with an expected payoff of $0.5 \times \$ 38.50+0.5 \times \$ 1.00=\$ 19.75$. Lottery $B$ is better as it yields a utility difference of $\$ 1.75$. Now consider a risk-averse person, with $r=0.5$. For the same lottery choice 5 , this person uses their utility from money function $\mathrm{u}(\mathrm{x})$ to compare the expected utility they get from choice A, $0.5\left(20^{0.5} / 0.5\right)+0.5\left(16^{0.5} / 0.5\right)=\$ 8.47$ with their expected utility from choice $\mathrm{B}, 0.5\left(35.5^{0.5} / 0.5\right)+0.5\left(1^{0.5} / 0.5\right)=\$ 7.2$, a difference of $\$ 1.2$. Thus, for lottery 5 , this risk-averse individual prefers lottery A to lottery B. Risk-loving types $(r<0)$ make optimal pairwise decisions in the opposite direction (more B choices), using the same logic.

Holt and Laury ${ }^{10}$ have provided cut-off values for $r$ such that individuals prefer a certain discrete number (1-10) of A choices (and the rest B choices). Collapsing 
across their categories yields four groups: "risk lovers" ( $r<-0.15$; $0-3$ A choices) "risk neutral" $(-0.15<r<0.15$; four A choices), "mildly risk averse" $(0.15<r<0.68$; $5-6$ A choices), and "highly risk averse" ( $r>0.68$; seven or more A choices). These cut-off values for $r$ are related to the discreteness of the probability of earning the higher amount, which increase in increments of 0.10 . A finer increment for that probability would lead to smaller bins for $r$.

In our elicitation procedure, participants completed the lottery choice task twice, once for training, in which they were explicitly told that they would not receive any winnings, and then once more for payment. Specifically, they were instructed that one of their 10 choices would be randomly selected, and the lottery they chose, A or B for that choice would be carried out and they would keep the monetary earnings. As Table 1 shows, we designed the lottery so that everyone would earn something - either $\$ 38.50, \$ 20.00$, $\$ 16.00$, or $\$ 1.00$. Training was important to ensure that participants understood the task and procedure. After making a choice in each of the ten lotteries (choice A or B), they rolled a ten-sided die once to determine which of the ten choices would be paid and then a second time to determine their actual winnings from the option (A or B) they had selected for the randomly selected choice.

Returning to the example above, if the first die roll was a 5 , the payoff would be based on the participant's fifth choice. If, for the fifth choice, the participant chose $\mathrm{A}$ and the second die roll resulted in a 6 or more, he or she would win $\$ 16.00$; if a 5 or less was rolled, the person would win $\$ 20.00$. In pilot testing, we tried a computerized version, in which a random number generator replaced the ten-sided die roll, but participants preferred the active involvement of rolling the die and we used this method for data collection.

All participants, young and old, were able to complete the task. Mean earnings were $\$ 22.17$ (standard deviation [SD], \$11.73), which did not differ between young and older adults. One young and nine older participants made at least one inconsistent lottery choice (that is, chose a B option and on the next lottery switched back to A). However, the proportion of inconsistent choices relative to all choices overall was small ( $<1 \%$ among young, $5 \%$ among old).

\section{Eliciting time preference}

In addition to eliciting risk aversion, we elicited individual time preferences. Table 2 shows the elicitation used to establish time preference, which utilizes a version of the methodology for assessing individual discount rates developed in
Table 2 Discount rate elicitation task

\begin{tabular}{lllll}
\hline $\begin{array}{l}\text { Choice } \\
\text { number }\end{array}$ & $\begin{array}{l}\text { Option A: } \\
\text { in I month } \\
\text { receive }\end{array}$ & $\begin{array}{l}\text { Option B: } \\
\text { in } 7 \text { months } \\
\text { receive }\end{array}$ & $\begin{array}{l}\text { Annual interest } \\
\text { rate* (percent) }\end{array}$ & $\begin{array}{l}\text { Your } \\
\text { choice? } \\
\text { A or B? }\end{array}$ \\
\hline 1 & $\$ 3000$ & $\$ 3077$ & 5.08 & $\mathrm{~A} \mathrm{~B}$ \\
2 & $\$ 3000$ & $\$ 3157$ & 10.25 & $\mathrm{~A} \mathrm{~B}$ \\
3 & $\$ 3000$ & $\$ 3241$ & 15.55 & $\mathrm{~A} \mathrm{~B}$ \\
4 & $\$ 3000$ & $\$ 3329$ & 21.00 & $\mathrm{~A} \mathrm{~B}$ \\
5 & $\$ 3000$ & $\$ 3421$ & 26.55 & $\mathrm{~A} \mathrm{~B}$ \\
6 & $\$ 3000$ & $\$ 3517$ & 32.22 & $\mathrm{~A} \mathrm{~B}$ \\
\hline
\end{tabular}

Notes: *Calculation assumes interest is compounded monthly. Participants do not see annual interest rate.

Coller and Williams ${ }^{11}$ and Harrison et al. ${ }^{12}$ Specifically, we asked respondents whether they preferred $\$ 3000$ in 1 month from now or $\$(3000+\mathrm{X})$ in 7 months. For the latter, we incrementally increased $\mathrm{X}$ in six steps in amounts varying from an extra $\$ 157$ to $\$ 517$, implying annual interest rates between $5 \%$ and $32 \%$ (assuming interest is compounded monthly, as in the US banking system). Participants were told to imagine they could have $\$ 30001$ month from now or the various greater amounts if they were willing to wait an additional 6 months. Both options specified future income amounts to make them comparable (as opposed to offering an immediate \$3000).

If a participant chose Option A over B, then we inferred that the annual rate at which he or she discounts future income must be greater than the annual interest rate earned from choosing Option B. On the other hand, once Option B is chosen, we could infer that the individual's annual rate of discount must be less than or equal to the annual interest rate earned from choosing Option A. As in the risk-aversion elicitation task, most subjects switched from choosing option A to option B once and then maintained B choices. A higher rate of discount (consistently more A choices) implies a lower expected utility from future income or greater "impatience," while a lower rate of discount (consistently more B choices) implies the opposite, more "patience" or greater willingness to wait for future consumption.

We note that this kind of analysis presumes that individuals are risk-neutral expected-utility maximizers. As Anderson et al ${ }^{13}$ show, if agents are instead risk averse, then the rates of time preference elicited in the manner described here will be biased upward and this bias can be corrected using risk-aversion measures. However, our concern is not so much with the accuracy of the time and risk measures as with exploring whether there are differences by age in risk and time preferences.

All participants completed the second task. No young respondent made an inconsistent choice and only one older 
respondent made a single inconsistent choice. Unlike the risk-aversion elicitation task, the time preference task was unpaid and purely hypothetical.

\section{Analyses}

Because of the need to pay lottery winnings to participants to properly incentivize decision making (in addition to the $\$ 10$ gift card incentive), the sample was small. Analyses were limited to nonparametric tests (Mann-Whitney U, Wilcoxon $\mathrm{W}$ ) of differences in risk aversion and time preference between old and young participants. Because the two groups differed in gender, education, and income, additional analyses were conducted that limited analyses to groups with comparable socioeconomic status.

\section{Results}

Young adults $(\mathrm{n}=26)$ were aged $31.9(\mathrm{SD}, 4.7)$ years; older adults $(\mathrm{n}=34), 71.2(\mathrm{SD}, 8.4)$ years, $P<0.001$. The two groups differed in education, with young adults completing a mean of 17.3 years $(\mathrm{SD}, 1.9)$ and older adults 13.0 (SD, 3.2), $P<0.001$. All young adults had completed high school, while six of the older adults had not. We accordingly excluded these six elders from some analyses. All of the young adults were women, as were $82.4 \%$ of the older adults. Half the sample was African-American. None of the older adults met criteria for dementia (mean Mini-Mental State Exam 26.3, SD 2.6) or major depressive disorder.

Among older adults, performance on the two elicitation tasks was unrelated to performance on the Mini-Mental State Exam ( $r=-0.07$ for Holt-Laury, $r=-0.11$ for time preference; $P>0.50$ for both correlations), suggesting that the assessments were not strongly related to memory performance or attention in this sample.

Figure 1 shows differences in risk aversion for the two age groups. While both groups were overall risk averse, confirming findings from Holt and Laury, ${ }^{10}$ young adults

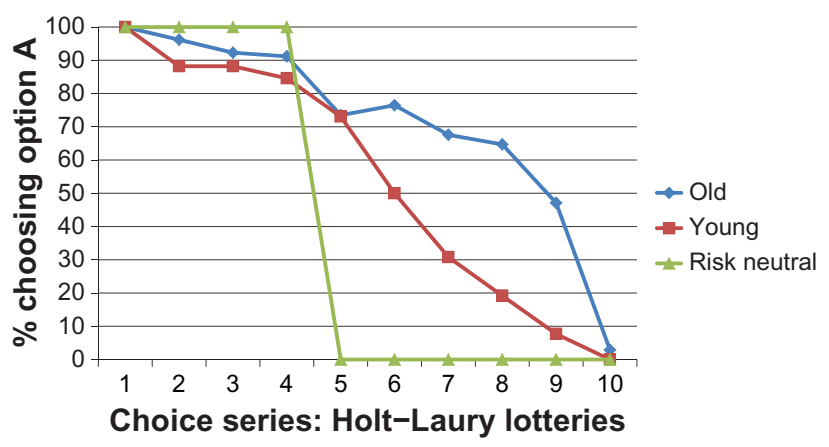

Figure I Risk aversion by age group. were closer to the risk-neutral benchmark and elders more risk averse.

Because of differences in education, we restricted further analyses to older adults completing high school, as shown in Table 3. Nonparametric tests for the individual lottery choice data show that the young adult group made significantly fewer A choices and was therefore less risk averse than the older adults in the sample (5.5 versus 6.8 A choices, $P=0.045$ ).

A similar difference was evident for elicited discount rates. Younger adults made an average of two A and four B choices, indicating a discount rate in the range $10.3 \%-15.5 \%$. Older adults made an average of $3.75 \mathrm{~A}$ and $2.25 \mathrm{~B}$ choices, indicating a discount rate in the range of $15.6 \%-21.0 \%$. As shown in Table 3, younger people made significantly fewer A choices, indicating they were willing to wait an additional 6 months for greater increments of money as compared with older adults $(P=0.003)$.

Table 3 Differences in risk aversion and time preference by age

\begin{tabular}{|c|c|c|}
\hline & $\begin{array}{l}\text { Young } \\
\text { adults \% (n) }\end{array}$ & $\begin{array}{l}\text { Older } \\
\text { adults \% (n) }\end{array}$ \\
\hline \multicolumn{3}{|l|}{ Less than 12 years of education } \\
\hline \multicolumn{3}{|l|}{ Lottery risk aversion, \% (n) } \\
\hline Risk lovers & - & $0(0)$ \\
\hline Risk neutral & - & $0(0)$ \\
\hline Mildly risk averse & - & $0(0)$ \\
\hline Highly risk averse & - & $100(6)$ \\
\hline Mean A choices & - & 7.8 \\
\hline \multicolumn{3}{|l|}{ Individual discount rates (dr) } \\
\hline 0 A choices, dr5 $[0.00,5.08]$ & - & $16.7(1)$ \\
\hline I A choice, dr5 [5.08, 10.25] & - & $33.3(2)$ \\
\hline 2 A choices, dr5 [10.25, 15.55] & - & $0.0(0)$ \\
\hline 3 A choices, dr5 [15.55, 21.00$]$ & - & $0.0(0)$ \\
\hline 4 A choices, dr5 [2I.00, 26.55] & - & $0.0(0)$ \\
\hline 5 A choices, dr5 $[26.55,32.22]$ & - & $0.0(0)$ \\
\hline 6 A choices, $\mathrm{dr}>32.22$ & - & $50.0(3)$ \\
\hline Mean A choices & - & 3.33 \\
\hline \multicolumn{3}{|l|}{ More than 12 years of education } \\
\hline \multicolumn{3}{|l|}{ Lottery risk aversion, \% (n) } \\
\hline Risk lovers & II.5 (3) & $10.7(3)$ \\
\hline Risk neutral & II.5 (3) & $10.7(3)$ \\
\hline Mildly risk averse & $46.2(12)$ & $29.4(5)$ \\
\hline Highly risk averse & $32.0(8)$ & $68.0(17)$ \\
\hline Mean A choices & 5.5 & $6.8 \quad P=0.045$ \\
\hline \multicolumn{3}{|l|}{ Individual discount rates (dr) } \\
\hline 0 A choices, dr5 $[0.00,5.08]$ & $19.2(5)$ & $7.2(2)$ \\
\hline I A choice, dr5 [5.08, 10.25] & $26.9(7)$ & $10.7(3)$ \\
\hline 2 A choices, dr5 [10.25, I5.55] & $19.2(5)$ & $17.9(5)$ \\
\hline 3 A choices, dr5 [15.55, 21.00$]$ & $15.4(4)$ & $7.2(2)$ \\
\hline 4 A choices, dr5 [2I.00, 26.55] & II.5 (3) & $10.7(3)$ \\
\hline 5 A choices, dr5 $[26.55,32.22]$ & $3.9(1)$ & $14.3(4)$ \\
\hline 6 A choices, $d r>32.22$ & $3.9(1)$ & $32.1(9)$ \\
\hline Mean A choices & 2.0 & $3.75 \quad P=0.003$ \\
\hline
\end{tabular}

Note: Significance assessed by Mann-Whitney test. 
Analyses limited to women (26 young and 24 old, educated to at least high school level) showed the same differences. The older group was more risk averse (7.2 versus 5.5 A choices, $P=0.002$ ) and had a higher discount rate $(15.6 \%-21.0 \%$ versus $10.3 \%-15.5 \%)$.

Repeating the analyses with control for differences in income also produced similar results. We first limited the analysis to people reporting less than $\$ 50,000$. Elders were more risk averse than young people in the lottery game $(P=0.04)$ and in elicited time preference $(P=0.03)$. We then limited the analysis to people reporting less than $\$ 35,000$. Elders were again more risk averse than young people, but differences were no longer significant in the lottery game and were marginally significant for time preference $(P=0.07)$.

The same was true when we compared younger people with older within race categories. Older age was associated with a greater number of A choices, hence greater discount rates, for both race groups. African-American respondents were more likely to show a higher rate of discount (consistently more A choices) and a lower expected utility from future income at every age, but the race term was not significant in an exploratory regression model that included age and race.

In this sample, risk aversion and implied discount rates were correlated, but the association did not reach significance $(\mathrm{r}=0.18, P=0.11)$. Greater risk aversion was associated with higher discount rates in both young and older adult samples.

\section{Discussion}

Using a small but representative sample of young and older adults drawn from community settings, the research confirms risk aversion overall in both young adults and older people but with greater risk aversion in older people. A second, experimental elicitation of time preference also showed differences between the age groups. Older people in this sample had higher average discount rates than young adults.

These findings are consistent with studies of financial risk taking and portfolio management across different age groups. For example, in a study of three waves of the Survey of Consumer Finances (SCF), a triennial survey conducted by the US Federal Reserve, Jianakopolos and Bernasek ${ }^{14}$ tracked the ratio of risky assets (assets with variable returns) to total investment wealth and noted strong effects for age. The mean ratio declined from 0.65 to 0.40 across people ranging in age from their $30 \mathrm{~s}$ to $70 \mathrm{~s}$. This analysis further adjusted for household factors, demographic indicators, labor supply factors, cohort, and types of assets. The shift away from risky assets at older ages is consistent with greater risk aversion and higher discount rates.

Further support for these age differences is evident in an alternative experimental elicitation of risk aversion. Gachter, Johnson, and Herrman ${ }^{15}$ developed an endowment effect experiment in which people were randomly given a good or not, which was not revealed to them until the end of the experiment. Respondents were queried regarding the price they would be willing to sell the good ("willingness to accept" [WTA]) in case they owned the good, as well as the price they would be willing to pay if they did not own the good ("willingness to purchase" [WTP]). A positive difference (WTA - WTP) is considered evidence for loss or risk aversion. ${ }^{16}$ In this sample of 360 employees of a car manufacturer, aversion to loss increased with age; the WTA/ WTP ratio increased from 1.5 to 5 from the youngest to oldest respondents (age 64+). The age difference was robust in regression models that adjusted for wealth, income, and education.

In a second elicitation of risk aversion, Gachter and colleagues ${ }^{15}$ used a lottery choice task similar to the HoltLaury paradigm used here. Individuals had to decide whether to play up to six lotteries and potentially win $£ 6$ or lose between $£ 2$ and $£ 7$ across the six lotteries, incremented by a loss of $£ 1$ with each lottery. Probabilities of winning were fixed at $50 \%$ based on a coin toss. At the end of the experiment, one lottery was randomly selected for payment. Under risk neutrality people should play the first five lotteries, which all have positive expected values (relative to loss of £2-£6), and decline the sixth (relative to loss of £7). However, only $12.6 \%$ accepted the five lotteries. Notably, older people (age 64+) on average accepted only the first two lotteries, while younger people accepted the first four lotteries.

Evidence for age differences in discount rates using experimental paradigms similar to the one used here is more mixed. In a large population-based Danish study, Harrison et $a l^{13}$ found increases in discount rates with greater age and retirement status. Differences by age were small (2\%), however, though larger for retirement status adjusted for age $(10 \%)$. An earlier study did not find age differences when respondents were matched by income levels. ${ }^{17}$ However, this early study differed from the one used here in two ways. First, participants had the choice between immediately receiving money versus our 1-month delay. Second, the experiment varied delay time, not interest rates. These differences may not make the experiments directly comparable. Finally, one study reported greater discounting among young and older adults relative to middle-aged people. ${ }^{18}$ 
Evidence from both financial portfolio management and alternative experimental elicitations of risk aversion (or more specifically, aversion to loss), then, generally support the greater risk aversion among older people established in our use of the Holt-Laury lotteries. These findings broadly support research showing older adults are more risk averse.

This research may be useful in light of recent research suggesting that neural activity scales directly with expected utility in decision tasks. ${ }^{19}$ Differences identified here in behavioral economic tasks suggest there may be differences in age-related activation patterns in brain regions involved in decision making, such as the lateral intraparietal area and regions of the frontal cortex. The low correlation between risk aversion and time preference in the sample suggests different brain regions may be involved. Neuroimaging of young and older people making the lottery decision and time preference tasks may shed light on changes in activation patterns over the lifespan.

Limitations of this research include differences in gender, education, and income between the age groups. We restricted analyses to women alone, excluded older adults who did not complete high school, and repeated analyses eliminating higher-income younger adults. Age differences persisted. Still, larger samples are required for a definite separation of age and confounding sociodemographic factors.

A second limitation involves the cognitive demand of the Holt-Laury paired-choice lottery mechanism. It presupposes a consistent response to the lotteries, with monotonic valuations of the lotteries as the probability of winning greater sums in the B option increases. In our sample, one younger adult and nine older adults failed to make fully monotonic choices. Thus, over a third of the older adults who had completed high school, compared with just fewer than $5 \%$ of younger adults, made nonmonotonic choices. These inconsistent responses are not easily attributed to mistakes, as participants first participated in a training trial. However, nonmonotonic choices are common in other studies using the paired lottery mechanism. Indeed, Holt and Laury ${ }^{10}$ report that $13 \%$ of their sample of university subjects, which included faculty as well as students, made nonmonotonic choices. Gachter and colleagues ${ }^{15}$ reported that $12.6 \%$ of the working auto employees in their sample gave nonmonotonic valuations. In both of these studies, participants were considerably younger than our older adult sample. How to handle nonmonotonic responses is unclear. Gachter ${ }^{15}$ excluded these respondents; Holt and Laury ${ }^{10}$ did not. Because the proportion of such responses overall was small in our sample relative to the total number of choices people made ( $5 \%$ in older adults, $<1 \%$ in young adults), we did not exclude them.

Given the key decisions that older adults need to make regarding insurance coverage, medical treatment, and finances, it is important to understand factors influencing decision making in later life. Our findings support prior research indicating greater risk aversion and higher discount rates among older adults relative to younger adults. Recognizing this difference may prove valuable in thinking about how to present choice situations to older adults. Indeed, evidence is now available to show that appropriate decision aids may reduce the effect of risk aversion on optimal financial choices. ${ }^{20}$

\section{Acknowledgment}

The authors thank Charity Reid for conducting assessments.

\section{Disclosure}

This research was funded by the University of Pittsburgh Claude D Pepper Older Adults Independence Center, P30 AG024827, a University of Pittsburgh Computational Public Health pilot award, and the University of Pittsburgh Multiple Infectious Disease Agents Study (MIDAS), U54 GM088491. The authors report no conflicts of interest in this work.

\section{References}

1. Denburg NL, Tranel D, Bechara A. The ability to decide advantageously declines prematurely in some normal older persons. Neuropsychologia. 2005;43(7):1099-1106.

2. Wood S, Busemeyer J, Koling A, Cox CR, Davis H. Older adults as adaptive decision makers: Evidence from the Iowa Gambling Task. Psychol Aging. 2005;20(2):220-225.

3. Deakin J, Aitken M, Robbins T, Sahakian BJ. Risk taking during decision-making in normal volunteers changes with age. $J$ Int Neuropsychol Soc. 2004;10(4):590-598.

4. Henniger DE, Madden DJ, Huettel SA. Processing speed and memory mediate age-related differences in decision making. Psychol Aging. 2010;25(2):262-270.

5. Carstensen LL, Mikels JA, Mather M. Aging and the intersection of cognition, motivation, and emotion. In: Birren J, Schaie KW, editors. Handbook of the Psychology of Aging. 6th ed. San Diego, CA: Academic Press; 2006:343-362.

6. Mather M. A review of decision-making processes: weighing the risks and benefits of aging. In: Carstensen LL, Hartel CR, editors. When I'm 64. Washington DC: National Academies Press; 2006:145-173.

7. De Martino B, Kumaran O, Seymour B, Dolan RJ. Frames, biases, and rational decision-making in the human brain. Science. 2006;313(5787):684-687.

8. Mikels A, Reed AE. Monetary losses do not loom large in later life: age differences in the framing effect. J Gerontol B Psychol Sci. 2009; 64(4):457-460.

9. Samanez-Larkin GR, Gibbs SE, Khanna K, Nielsen L, Carstensen LL, Knutson B. Anticipation of monetary gain but not loss in healthy older adults. Nature Neurosci. 2007;10(6):787-791.

10. Holt CA, Laury SK. Risk aversion and incentive effects. American Econ Rev. 2002;92:1644-1655. 
11. Coller M, Williams MB. Eliciting individual discount rates. Experimental Econ. 1999;2:107-127.

12. Harrison GW, Lau MI, Williams MB. Estimating individual discount rates in Denmark: A field experiment. American Econ Rev. 2002;92:1606-1617.

13. Anderson S, Harrison GW, Lau MI, Rutstrom EE. Eliciting risk and time preferences. Econometrica. 2008;76:583-618.

14. Jianakopolos NA, Bernasek A. Financial risk taking by age and birth cohort. South Econ J. 2006;72:981-1001.

15. Gächter S, Johnson EJ, Herrman A. Individual-Level Loss Aversion in Riskless and Risky Choices. Discussion Paper No. 2961. Bonn: Forschungsinstitut zur Zukunft der Arbeit/Institute for the Study of Labor; 2007. Available from: http://ftp.iza.org/dp2961.pdf. Accessed January $24,2012$.
16. Tversky A, Kahneman D. Loss aversion in riskless choice: A referencedependent model. Quart J Econ. 1991;106(4):1039-1061.

17. Green L, Myerson J, Lichtman D, Rosen S, Fry A. Temporal discounting choice between delayed rewards: The role of age and income. Psychol Aging. 1996;11(1):79-84.

18. Read D, Read NL. Time discounting over the lifespan. Organ Behav Hum Decis Process. 2004;94:22-32.

19. Sanfey AG, Lowenstein G, McClure SM, Cohen JD. Neuroeconomics: Cross-currents in research on decision-making. Trends $\mathrm{Cog} S \mathrm{Sc}$. 2006;10(3):108-116.

20. Samanez-Larkin GR. Wagner AD, Knutson B. Expected value information improves financial risk taking across the adult life span. Social Cog Affect Neurosci. 2011;6(2):207-217.

\section{Publish your work in this journal}

Neuroscience and Neuroeconomics is an international, peerreviewed, open access journal focusing on the identification of brain structures and measurement of neural activity related to behavior, behavioral predictions, and decision making in health and disease.
Visit http://www.dovepress.com/testimonials.php to read real quotes from published authors. 